\title{
EGFR Gene Alteration Positive
}

National Cancer Institute

\section{Source}

National Cancer Institute. EGFR Gene Alteration Positive. NCI Thesaurus. Code C157585.

A finding indicating that mutation, overexpression or rearrangement of the EGFR gene has been detected in a sample. 